\title{
Review
}

\section{The Science of Social: Beyond hype, likes \& followers}

\author{
Michael Wu \\ Lithium Technologies, 2012; 94pp; eBook, free from lithium.com; \\ ASIN: B006ZNN602
}

Journal of Direct, Data and Digital Marketing Practice (2012) 14, 180-181. doi:10.1057/dddmp.2012.27

\section{A book of two parts}

The power of the

1 per cent
Social media is a market place deluged with blogs, experts and books telling us how to tap into the socially connected customer. The Science of Social explains how to unlock the value of your social community. It focuses on a single proposition: the gamification of your customers and superfans to create an active and motivated community that will add value.

Maybe it's a reflection of the immature nature of social media adoption, but $\mathrm{Wu}$ starts the book with a more basic, and oft repeated, explanation of social marketing concepts. It is hard not to switch off when faced with the usual 'social media myth-busting' chapter filled with the usual rhetoric about not broadcasting messages, the need for dialogue and engaging audiences. And maybe I am just too cynical, but it was even more tempting to put the book away when I saw the words 'paradigm shift', 'Attention Economy' and thinly disguised promotions of his company (and the publishers of the book).

But I urge you to press on past the introduction and first chapter.

$\mathrm{Dr} \mathrm{Wu}$ offers incredible insight into the social media opportunity. He brings science and logic to the complexity of reputation, relationships and influence in social networks. Better still he explains in clear steps how to isolate the valuable 'superfan'; how to motivate and change behaviours; and most importantly, how to create a deeply engaged community that will generate business value.

Wu peppers the book with easily digestible (and fact and statistics filled) case studies. He presents well-reasoned and pragmatic arguments for creating a community and building strong relationships with customers.

While proving the value of the community-based approach through plenty of examples, he also gives you the tools to put influence in the context of the purchase funnel. Useful when thinking about how you might isolate the return on your investment from social media.

'Influence' is the most overused phrase in social, bandied around in replacement of 'audiences', without any real understanding of the worth of a truly influential customer.

$\mathrm{Wu}$ brings clarity to the subject with a well-defined and structured approach to influence in a deliciously detailed chapter, which is worth 
reading at least twice. He identifies the six factors of influence, going on to explain how influence is connected, and sometimes transient; the way it changes behaviours and how to create relationships with the business.

According to $\mathrm{Wu}$, 'superfan' is the term for your most influential, prolific and knowledgeable customers. It is this 1 per cent of your community that is most powerful in driving your community. This tiny percentage ensures you can scale your social media and manage a community of millions. And according to $\mathrm{Wu}$, it is your relationships with superfans that can move your bottom line.

A bold claim, but one $\mathrm{Wu}$ goes on to explain, is founded in a need for trust, openness and transparency. Explaining the difference between weak and strong ties, he suggests that success can be found in creating relationships with a small number of customers who want to have an intense level of engagement with the business.

$\mathrm{Wu}$ goes beyond the theory, and brings the argument back to how businesses can benefit from a closer relationship with customers with delightfully pragmatic advice. All the way along, Wu uses statistics, insights and proof cases to demonstrate the argument for a focus on superfans.

Quite rightly, Dr Wu believes that social media is not about the number of fans, or superfans for that matter, but instead the value of social media is in engagement - persistent customer actions, loyalty and interactions.

'The ultimate goal of dynamic, adaptive gamification', according to $\mathrm{Wu}$, 'is to create initial and lasting engagement'. So now we get to the core argument in the book: how to motivate and change behaviours using gamification.

$\mathrm{Dr} \mathrm{Wu}$ has been a great proponent of gamification. In fact, his company is built on this concept. He talks regularly on the subject and expands his thinking in his blog.

A complex theory, Wu takes you through the thinking, often in quite an academic way. Bringing together Fogg's behaviour model; Maslow's hierarchy of needs; Skinnerian conditioning; and Daniel Pink's intrinsic motivators to create an argument for gamification, $\mathrm{Dr} \mathrm{Wu}$ believes that great gaming dynamics and 'fun' are the cornerstones of an active and motivated community. Weaving in the value of relationships, the need for trust and the scalable value of superfans, he does much to bring the science of social together into a single approach.

Having studied physics, natural science and mathematics, it is no surprise that $\mathrm{Dr} \mathrm{Wu}$ enjoys untangling the complex to create a clear path to better customer engagement through social media. His book is an absorbing read. While occasionally it drifts into academic theory, $\mathrm{Dr} \mathrm{Wu}$ includes lots of examples, highlighted points, lists and side notes that make your journey through the science of social both pragmatic and interesting.

If you are serious about harnessing the value of social media, this book is one to add to your reading list. 